\title{
Habitat deterioration relaxes resource competition and sexual selection in the threespine stickleback
}

\section{Henriksson, Eva}

2020-12

Henriksson , E \& Candolin , U 2020 , ' Habitat deterioration relaxes resource competition and sexual selection in the threespine stickleback ' , Oikos, vol. 129 , no. 12 , pp. 1773-1780 . https://doi.org/10.1111/oik.07750

http://hdl.handle.net/10138/322234

https://doi.org/10.1111/oik.07750

submittedVersion

Downloaded from Helda, University of Helsinki institutional repository.

This is an electronic reprint of the original article.

This reprint may differ from the original in pagination and typographic detail.

Please cite the original version. 
Habitat deterioration relaxes resource competition and sexual selection in the threespine stickleback

\section{Abstract}

The operation of sexual selection depends on ecological conditions. Thus, changes in environmental conditions because of human activities can alter the strength and direction of sexual selection, with implications for evolutionary trajectories and the viability of populations. We show that aquatic algal blooms can relax the operation of sexual selection by influencing which males are available to attract females. This is by influencing the ability of males to maintain a resource needed in mate attraction. When we exposed two competing threespine stickleback males (Gasterosteus aculeatus), whose attractiveness to females was known, to either clear or algal-turbid water, nest abandonment was more common in clear water, and it was usually the unattractive male that abandoned his nest. In turbid water, on the other hand, nest abandonments were less common and when they occurred, the probability increased that the attractive male abandoned his nest, and that the unattractive male subsequently occupied it. This change in the composition of nesting males increased the mating success of unattractive males. Thus, our results reveal a new mechanism through which habitat deterioration can influence sexual selection, by altering success in the competition for a resource critical in mate attraction, a territory with a nest in this case. This could be a common mechanism, considering the prevalence of resource competition in mate choice systems. On a broader level, our results emphasise the importance of considering the impact of environmental changes on the outcome of resource competition when investigating the influence that environmental disturbances have on the operation of sexual selection and thereby on evolutionary processes and population dynamics. 


\section{Introduction}

Human activities are altering habitats at an alarming rate. This is influencing evolutionary processes, including sexual selection (Candolin and Wong 2019, Martinossi-Allibert et al. 2019, Rosenthal and Stuart-Fox 2012, Swaddle et al. 2015). Several studies find habitat alteration to influence the ability of females to find males (e.g. Gurule-Small and Tinghitella 2018, Heuschele et al. 2012, Myhre et al. 2013, Schmidt et al. 2014) or make informed mate choices (Coomes et al. 2019, des Aunay et al. 2014, Iglesias-Carrasco et al. 2017), and thereby to alter the operation of sexual selection (Candolin 2019). However, habitat alteration can also influence which mates are available to choose among, which similarly could influence mate choice and sexual selection. Yet, this possibility has received little attention.

The possibility that habitat alteration influences the composition of available mates is especially likely in species where resources have to be competed for and monopolised for individuals to be able to attract mates. Environmental factors are known to influence the outcome of competition for resources in general, and the effect can even be larger than the effect of intrinsic properties of individuals (Lane and Briffa 2018). In support of an effect of environmental conditions on the competition for resources needed in mate attraction, a few studies find changes in the environment to alter the number of individual monopolising resources and, thus, being available as mates (e.g. Candolin et al. 2014, Candolin and Vlieger 2013, Ryder and Sillett 2016). However, whether such changes also influence the composition of the available mates is unknown. This is surprising as males of many species compete for territories, nest sites and resources essential in mate attraction, and changes in the environment could influence which males are successful in the competition (Andersson 1994). If large changes occur, female mate choice could be altered and influence the operation of sexual selection. Changes in sexual selection could, in turn, influence the ability of the species to adapt to the altered conditions, as sexual selection is a potent evolutionary force (Cally et al. 2019, Candolin and Heuschele 2008, Kingsolver et al. 2001, Parrett et al. 2019).

An emerging human-induced environmental problem in many aquatic ecosystems, which can influence the operation of sexual selection, is the occurrence of algal blooms. Enrichment with nutrients through human activities, i.e. cultural eutrophication, promotes the growth of algae, which can result in the sudden development of massive algal blooms, particularly when rising 
water temperatures make conditions favourable for algal blooms (Carstensen et al. 2015, Gobler et al. 2017, O'Neil et al. 2012, Thomas et al. 2012). Blooms vary in extent in time and space, and may fade away after a few days when nutrients have been used up or grazing has reduced their abundance, or, alternatively, when the conditions become less favourable because of decreasing temperature or currents bringing in cold or nutrient poor water (Carstensen, et al. 2015, SliwinskaWilczewska et al. 2019). Such rapid shifts in algae concentration and turbidity can influence the operation of sexual selection by reducing visibility and hampering the efficient use of visual signals and cues in mate choice, such as courtship activity and nuptial coloration (Candolin 2009, Seehausen et al. 1997, Sundin et al. 2017, van der Sluijs et al. 2011, Wong et al. 2007). However, changes in algal turbidity could also influence the composition of available mates and thereby alter mate choice. Reduced visibility during algal blooms could influence the willingness of individuals to invest in the competition for resources needed in mate attraction, particularly if reduced visibility decreases encounter rates with potential mates (Heuschele, et al. 2012) or the ability of individuals to gain or maintain resources needed for reproduction (Candolin, et al. 2014). The impact could vary depending on the phenotypic and genetic characteristics of the individuals and thereby alter the composition of the available mates. Such changes in mate composition could, in turn, influence the reproductive success of the individuals and thereby population dynamics. The changes could also alter the distribution of reproductive success among individuals and, thus, the evolutionary trajectory of the species.

An area that has been severely affected by eutrophication during the last decades is the Baltic Sea (Andersen et al. 2017, Korpinen et al. 2012). Excessive input of nutrients by humans has promoted primary production, which has increased the frequency and extent of algal blooms (Finni et al. 2001, Fleming-Lehtinen and Laamanen 2012). The blooms reduce visibility, which influences the mate choice system of species relying on visual cues for mate choice (Candolin 2009, Järvenpää and Lindström 2004). In particular, the nest brooding threespine stickleback (Gasterosteus aculeatus) has been affected by the blooms, as it reproduces in shallow water where intense algal blooms are common. Males build a nest to which they attract females to spawn, and then care alone for the eggs spawned into the nest until hatching (Wootton 1984). Reduced visibility hampers the ability of stickleback females to find nesting males (Heuschele, et al. 2012) and to evaluate their qualities, which can alter their mate choices (Engström-Öst and Candolin 2007, Heuschele et al. 2009). Whether algal blooms also influence which males are available to choose 
among is unknown. Yet, this is likely, as threespine stickleback males compete intensively for territories and nesting sites, and the ability of males to establish and defend territories, or their motivation to do so, could vary depending on environmental conditions.

We investigated if algal blooms influence the composition of threespine stickleback males available for females to choose among. We expected blooms to alter the composition of nesting males by increasing the probability that subdominant males are able to defend and maintain a territory with a nest in the presence of more dominant males. This is because deteriorating visibility reduces aggressive interactions among males (Candolin, et al. 2014, Candolin and Vlieger 2013), and this could increase the ability of subdominant males to establish and maintain a nest site under male-male competition. In addition, the willingness of attractive males to defend a nest site could decrease when visibility deteriorates, as poor visibility reduces the ability of females to detect males and evaluate their quality (Candolin et al. 2016), which decreases the quality of the nest site to attractive males. Correspondingly, the willingness of less attractive males to defend a nest site under algal blooms could increase, as their probability of mating could improve when the ability of females to judge male quality decreases.

Thus, we expected algal blooms to change the composition of nesting males towards an increased representation of subdominant, less attractive males, through reduced aggressive interactions among males and reduced willingness of attractive males to defend a poor nest site. Changes in the composition of available males could, in turn, influence the distribution of mating success among males. Females cannot postpone spawning after the eggs have been ovulated, but have to spawn within 1-2 days (Wootton 1984). Males, on the other hand, can postpone courtship and the attraction of females by waiting for conditions to improve. Postponing reproduction can be a profitable strategy for males when the probability of attracting females is low, but could improve in the future when the algal bloom have faded. This is because males have to enter the parental stage 1-2 days after receiving the first clutch of eggs (when they no longer court females) to ensure that all embryos in the nest are at the same developmental stage (Wootton 1984). The parental stage is the most time-costly stage as it takes about 2 weeks, depending on water temperature, until the hatched fry leave the nest. During the parental stage, the male fans fresh water into the nest, alters the structure of the nest according to the developmental stage of the embryos and hatched fry, and defends the offspring against predators, both con- and heterospecifics. The parental stage is consequently also energetically costly (Wootton 1984). 
Based on these predictions, we investigated (1) if a reduction in water visibility, equivalent to that associated with an algal bloom, influences the probability of a subdominant threespine stickleback male maintaining nest ownership under male competition, (2) if the probability of maintaining nest ownership under poor visibility depends on the attractiveness of the male to females, and (3) if changes in nest ownership under poor visibility influence the distribution of mating success among males. We first determined the attractiveness of two nesting males, and then allowed them to interact for one day in clear or algal turbid water to record dominance status and effects of turbidity on nest ownership. We recorded both nest abandonments and whether the other male took over the abandoned nest. Finally, we assessed the success of the two males in gaining fertilisations.

\section{Materials and methods}

\section{Collection and Housing}

Adult threespine stickleback were collected using Plexiglas traps (Candolin and Voigt 2001) at the start of the breeding season from the shores of the Baltic Sea in southern Finland $\left(60^{\circ} \mathrm{N}, 23^{\circ} \mathrm{E}\right)$. Fish were housed in large holding tanks with sea water (salinity $5.5 \mathrm{psu}$ ) at a density of 0.25 fish per litre, a photoperiod of $18 \mathrm{~L}: 6 \mathrm{D}$, and a temperature of $18^{\circ} \mathrm{C}$. The fish were separated by sex based on the development of eggs or nuptial coloration. Males were transferred to individual, aerated aquaria $(40 \times 35 \times 30 \mathrm{~cm})$ and given a nesting dish $(\varnothing 12.5 \mathrm{~cm})$ filled with sand and some filamentous algae, Cladophora glomerata, for nest construction (Candolin 1997). All aquaria were visually isolated from neighbouring aquaria. To encourage nest building, a gravid female in a perforated, transparent cup was presented to each male twice daily for $15 \mathrm{~min}$. All fish were fed twice daily ad libitum with frozen chironomid larvae. Only males that completed nest building within two weeks were used in the experiment.

\section{Female preference}

Experimental aquaria $(70 \times 40 \times 30 \mathrm{~cm})$ were divided into three aerated compartments using removable Plexiglas partitions: one transparent partition divided the aquarium into a front female compartment $(70 \times 10 \mathrm{~cm})$ and a back male compartment $(70 \times 30 \mathrm{~cm})$, and an opaque partition divided the back compartment into two adjoining male compartments $(35 \times 30 \mathrm{~cm}$, Figure 1$)$. Into 
each male compartment, a male was placed together with his nesting dish containing a completed nest. The males were randomly selected, but to ensure that the size difference between them would not be too large, pairs where the size difference was larger than $5 \mathrm{~mm}$ were discarded. The standard length and wet weight of the males were measured during transfer, and the males were marked by clipping the tip of one of the three dorsal spines. Their body condition was calculated as Fulton's Condition Factor K (Le Cren 1951). The distance between the nesting dishes, $50 \mathrm{~cm}$, corresponds to distances between nests in the field, where the density of territories can be high at preferred spawning sites, with up to three nesting males per $\mathrm{m}^{2}$ (Candolin 2004).

After the males had acclimatized for one day to the aquarium, a gravid female was placed into the middle of the front compartment from where she could see both males and their nests (Figure 1). She was first enclosed in a transparent Plexiglas cylinder (diameter $10 \mathrm{~cm}$ ), and released after 5 min of acclimatization. Her mate preference was recorded during $15 \mathrm{~min}$ by noting the time she spent within $5 \mathrm{~cm}$ of each male's compartment in a head-up posture, which indicates readiness to spawn (Tinbergen 1951). A female was judged to prefer one of the males when she spent at least $75 \%$ of her inspection time by that male. The mate preference of three females was recorded, with a 30 min break between female presentations. Each female was used only once. The experiment was continued for trials where all three females preferred the same male.

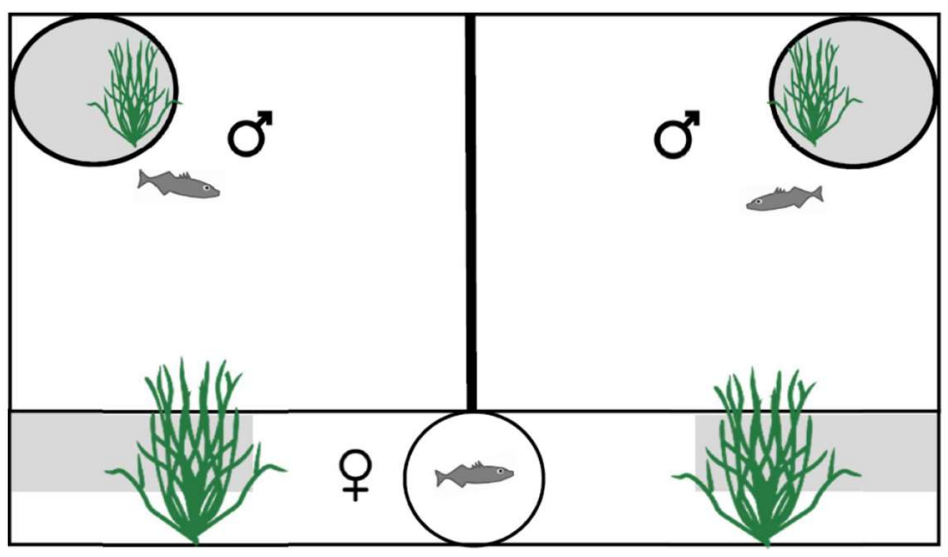

Figure 1. The experimental aquarium with the two male compartments visually isolated from each other with a removable opaque divider (before male interaction), and the female compartment isolated from the male compartments with a removable transparent divider. The location of the nesting dishes of the two males is indicated, as is the location of the transparent cylinder in which the female was held before being allowed to choose between the two males. The grey zones in the female compartment indicate the zones for determining mate preference. 
174

\section{Nest holding ability}

To investigate the influence of algal blooms on the ability of the males to maintain their nests when faced with a competing male, the two nesting males were exposed to either clear or algalturbid sea water. Algal turbidity was manipulated by adding a solution of the nontoxic flagellate algae Isochrysis sp. to the algal treatment to a level of 10 nephelometric turbidity units (NTU), while the same amount of clear sea water (NTU 1) was added to the clear-water treatment. The solution was added after the last female presentation over the course of $1 \mathrm{~h}$ to imitate the inflow of algae. Turbidity levels were measured with a portable nephelometer (Hach 2100P). The chosen algae is part of the phytoplankton community of the Baltic Sea, and was cultivated according to previously published methods (Vlieger and Candolin 2009). Turbidity in the Baltic Sea varies between 0.5 and 45 NTU, but rarely exceeds 30 NTU (Granqvist and Mattila 2004). The aquaria were continuously aerated to ensure algae survival. Two bunches of artificial vegetation were placed into the female compartment to serve as shelters for males that abandoned their nest during the next stage of the experiment (male interaction).

The males were allowed to acclimatize for $1 \mathrm{~h}$ to the turbid (or clear) water, after which all partitions were removed. After $24 \mathrm{~h}$ of direct interaction, the behaviour of the males and the size of their territories were determined by observing the males for $15 \mathrm{~min}$. The number of attacks on the other male was recorded for each male, and territory size was recorded as how far from the nest each male ventured, and where the boundary was set in replicates were both males maintained his territory. The identity of the nest owner(s) was noted. A gravid female (different from the ones that had been used to determine female mate preferences) was then released into the middle of the aquarium and followed until spawning occurred, or until two hours had passed if no spawning occurred. Her choice of nest and the identity of the male that fertilized her eggs were noted. Males, including males dispelled from their nest site, could attempt to fertilise the eggs spawned into the nest of the other male through sneak fertilisation (Vlieger and Candolin 2009).

To test whether water turbidity influenced the probability of nest abandonment and nest takeover, and whether the attractiveness of the male that abandoned his nest (preferred or not by females) differed between turbidity treatments, logistic regression was used. To test whether water turbidity influences whether the preferred or the non-preferred male abandoned the nest 
sites, Fisher's exact test was used. To test whether water turbidity and male attractiveness influenced attack rate by each male on the other male, a generalised linear mixed model (GLMM) with a Poisson probability distribution and a log link function was used (as the response variable was a count variable), with turbidity and male attractiveness as fixed factors and male pair as a random factor. To test for differences between the preferred and the non-preferred male in body size and condition, a paired t-test was used. To test for an effect of turbidity on female mate choice (after male interaction), logistic regression was used. All analyses were performed using the software package IBM SPSS Statistics v. 25 (Armonk, NY: IBM Corp.).

\section{Results}

Abandonment of the two nest sites by one of the two males during male-male interaction occurred more often in clear water (24 out of 26 ) than in algal turbid water (12 out of 26) (logistic regression: $b=2.64, S E=0.84$, Wald $=10.00, P=0.002)$. In no trials did both males abandon the nest sites. The attractiveness of the male that abandoned the nest sites differed between treatments $(b=2.28, S E=0.85$, Wald $=7.20, P=0.007$, Figure 2$)$ : in clear water the non-preferred male more often abandoned the nest sites (21 out of 24 abandonments), while there was no difference between the two males in nest abandonment in turbid water (non-preferred male abandoned in 5 out of 12 abandonments). Thus, the non-preferred male abandoned the nest sites less often in turbid water (21 out of 26 trials in clear water and 5 out of 26 trials in turbid water, Fisher's exact test, $\mathrm{p}<0.001$ ), while the attractive male did not differ in nest abandonments between clear and turbid water ( 3 out of 26 trials in clear water and 7 out of 26 trials in turbid water, $\mathrm{P}=0.29)$.

The intensity of direct male aggressive interactions, measured as attack rate, was lower in turbid water (GLMM: $\left.F_{1,100}=7.78, P=0.006\right)$ and differed between the preferred and the non-preferred male depending on water turbidity (interaction between turbidity and attractiveness: $F_{1,100}=10.60$ $P=0.002)$ : in clear water the preferred male performed more attacks than the non-preferred male, while there was no difference between the males in turbid water (Figure 3). When only one male maintained his territory after male interaction, he occupied the whole aquarium in clear water (territory size always $70 \mathrm{~cm}$ in width), with the other male hiding in the vegetation, while the territory was smaller in turbid water (mean width $=54 \mathrm{~cm}, \mathrm{SD}=10 \mathrm{~cm}$ ), with the non-nesting 
male moving more freely around. The preferred and the non-preferred males did not differ in body length (paired t-test: $t_{51}=1.58, P=0.12$ ), wet weight $\left(t_{51}=0.11, P=0.92\right)$, or body condition $\left(t_{51}=0.94, P=0.35\right)$.

Nest takeover after a male had abandoned his nest was more common in turbid water (6 out of 12) than in clear water ( 3 out of 24 , logistic regression: $b=1.94, S E=0.84$, Wald $=5.30, P=0.021$, Figure 4). In all trials with nest takeover, it was the non-preferred male that took over the abandoned nest of the preferred male, independent of turbidity treatment, while abandoning his self-built nest.

Female spawning decision was not influenced by water turbidity (females spawned in 19 out of 26 trials in both treatments), but she spawned more often with the non-preferred male in turbid water (10 out of 19 ) than in clear water ( 1 out of $19, b=3.00, S E=1.12$, Wald $=7.08, P=0.008$, Figure 5). The eggs were always fertilized by the nest owner (also when the nest had a new owner) and no successful sneaking occurred.

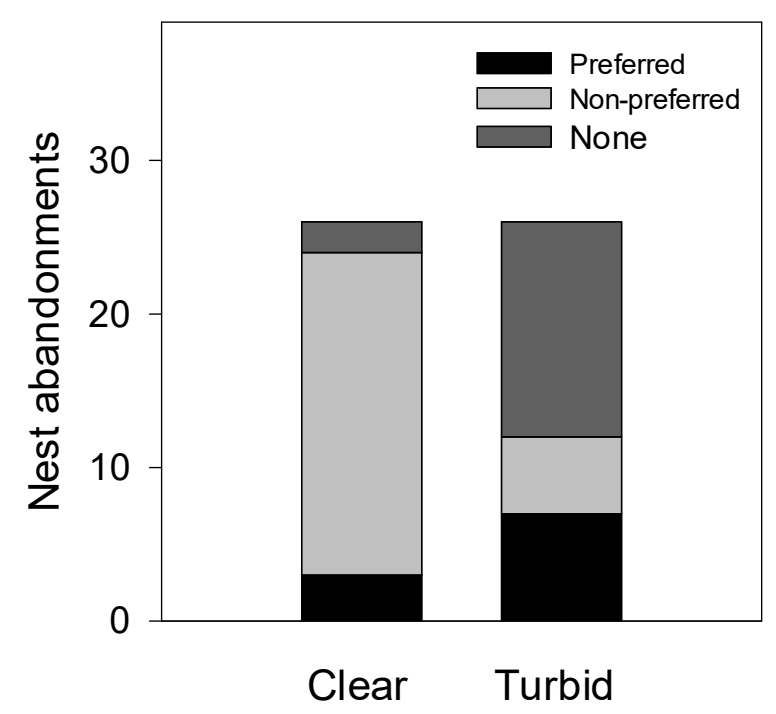

Figure 2. Number of trials in clear and algal turbid water in which a threespine stickleback male abandoned the two nest sites after $24 \mathrm{~h}$ of interaction with another male. Bars show whether the abandoning male had been preferred by females prior to interaction, and number of trials in which none of the two males abandoned the nest sites. In no trials did both males abandon the nest sites. 


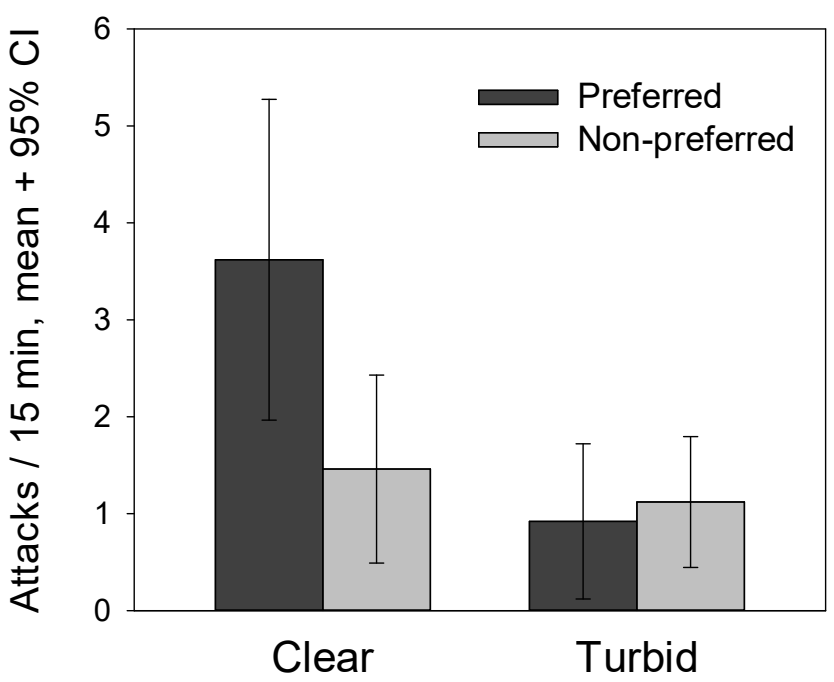

Figure 3. Attack rate per 15 min by two interacting threespine stickleback males in clear and turbid water. The preferred male had been preferred by three females prior to $24 \mathrm{~h}$ of male interaction.

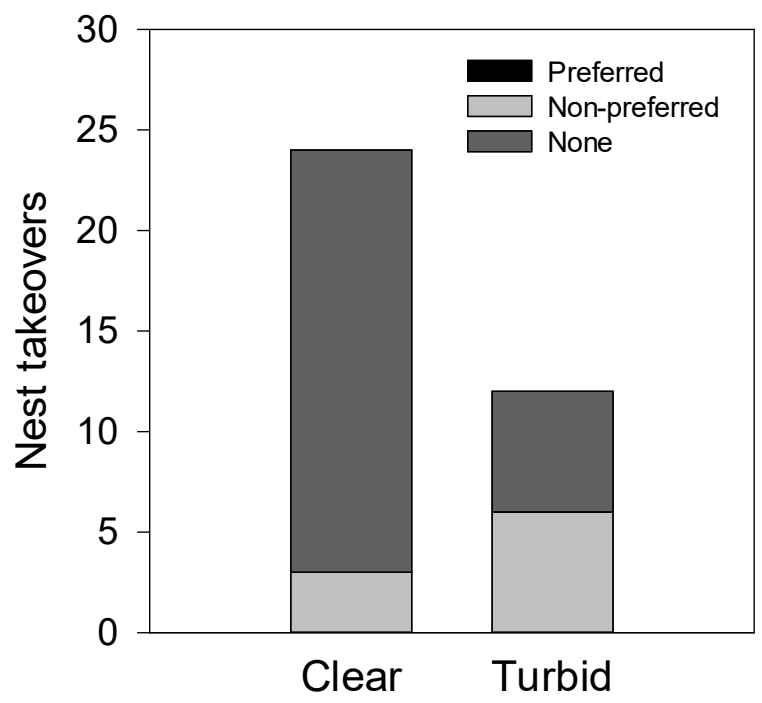

260 Figure 4. Number of trials in clear and turbid water in which a threespine stickleback male took 261 over an abandoned nest of another male after $24 \mathrm{~h}$ of male interaction (in trials where nest 262 abandonment had occurred). Bars show whether the male taking over the nest had been preferred 263 by females before male interaction, and number of trials in which none of the two males took over 264 the nest of the other male. 


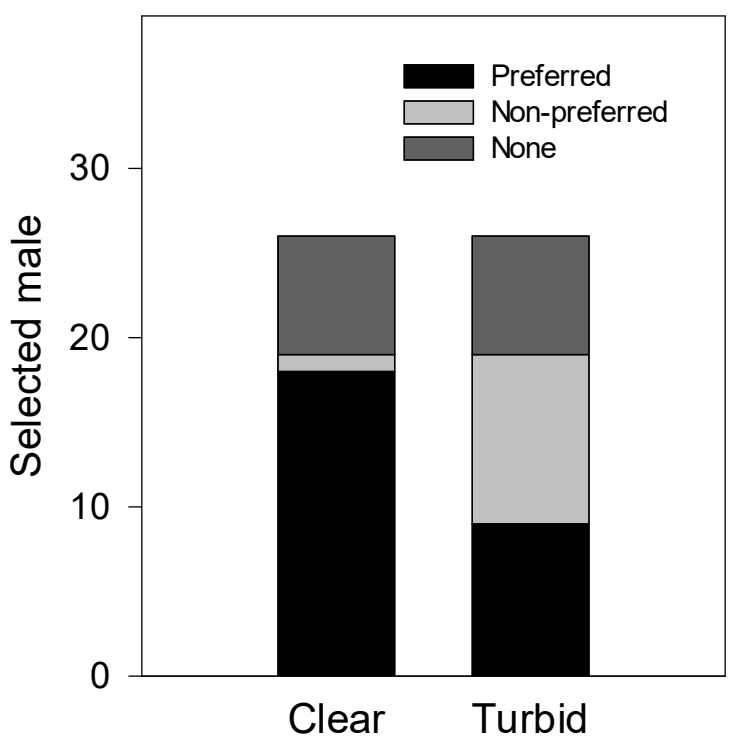

Figure 5. Number of trials in clear and algal turbid water in which a threespine stickleback female spawned, or did not spawn, with one of two interacting males. Bars show whether the chosen male had been preferred by females in clear water before $24 \mathrm{~h}$ of male interaction.

\section{Discussion}

Algal turbidity altered the composition of courting males available for females to spawn with. Unattractive males, which usually were subdominant males, more often hold on to their nest site in turbid water than in clear water when the attractive male maintained his nest site, and usually occupied the nest site of the attractive male when he abandoned his nest site. Thus, algal turbidity changed the composition of courting males towards unattractive ones, which, in turn, increased the probability that females would spawn with an unattractive male.

The cause of the improved ability of unattractive males to maintain a nest site in algal turbid water was probably relaxed male-male competition and a correlation between attractiveness and dominance. The attractive male was more aggressive in clear water than in turbid water and dominated over the unattractive male, which caused the unattractive male to abandon his nest site in clear water. In turbid water, on the other hand, the territories were smaller and the attack rate between the males was lower, which allowed the unattractive male to maintain his nest site despite the presence of the attractive male. This agrees with earlier studies that find reduced visibility to reduce the size of territories and relax aggressive interactions among males (Candolin, 
et al. 2014, Candolin and Vlieger 2013), as well as male attractiveness to correlate with male dominance (Candolin 1999). Our expectation of a decline in the willingness of attractive males to defend their nest site under turbid conditions was not upheld, as attractive males were not more likely to abandon their nest site when visibility deteriorated. However, when nest abandonments occurred in turbid water, the probability was higher that the attractive male was the male that abandoned his nest. The unattractive male often took over the abandoned nest of the attractive male, but the attractive male never changed nests by abandoning his self-built nest and taking over the nest of the unattractive male.

The higher probability that unattractive males would be nest owners in turbid water increased the probability that females would spawn with them. In clear water, male-male competition ensured that mostly attractive males were available for females to spawn with, which consequently facilitated female choice for these males. In turbid water, on the other hand, male-male competition was relaxed and unattractive males were more likely to hold on to their nest site Combined with an earlier recorded reduction in the ability of females to carefully evaluate males under poor visibility (Candolin et al. 2007, Candolin, et al. 2016, Engström-Öst and Candolin 2007, Wong, et al. 2007), this increased the probability that females spawned with an unattractive male.

Such changes in the composition and spawning success of nesting males are likely to occur in the field under algal blooms. Territories are smaller and aggressive interactions are less frequent in habitats with poor visibility (Candolin 2004, Candolin, et al. 2014), which should favour subdominant males, as shown in the present study. The distribution of mating success among nesting males is also more equal in habitats with poor visibility (Candolin 2004), which suggests that unattractive males have a higher probability of attracting females when visibility deteriorates. Thus, algae blooms are likely to influence the mating success of males in the field and thereby the strength of sexual selection. This could, in turn, influence the evolutionary trajectory of the species, by influencing the evolution of both sexually selected traits, such as red nuptial coloration and courtship behaviour, and naturally selected traits, such as dominance and general viability.

Altered distribution of mating success among males could influence also population dynamics through effects on the number and viability of offspring produced. Unattractive males generally sire less viable offspring than attractive males (Candolin, et al. 2016) and have a lower hatching success (Candolin 2000), which suggests that an increased mating success of unattractive males 
could influence offspring production and recruitment. Females usually prefer to spawn with dominant males that can defend the eggs in the nest against nest destroyers and egg predators, the main causes of failed reproductive success in the population (Candolin and Vlieger 2013). Unattractive, subdominant males could have a higher hatching success in turbid water than in clear water, because of fewer intrusions from competing males and possible predators, but their ability to defend the eggs and raise them to the hatching stage is likely to decrease when water conditions again improve, as algal turbidity can vary from day to day (Carstensen, et al. 2015, Sliwinska-Wilczewska, et al. 2019).

The impact that altered sexual selection in disturbed environments has on population viability is generally poorly known (Candolin and Heuschele 2008, Candolin and Wong 2019, Holman and Kokko 2013, Martinez-Ruiz and Knell 2017). Yet, considering the importance that sexual selection plays in both evolutionary processes and population dynamics (Cally, et al. 2019), more attention should be paid to the topic. Our results reveal a new mechanism through which environmental change can influence sexual selection, by altering the outcome of competition for resources needed in mate attraction and, thus, the composition of individuals available for mate choosers to select among. This could be a common mechanism, considering that males of many species compete fiercely for resources needed in mate attraction (Andersson 1994).

To summarise, our results show that algal blooms can increase the proportion of unattractive males available for females to mate with, which can increase the mating success of these males. This reveals an earlier unexplored pathway through which environmental disturbances can influence sexual selection: by altering the outcome of competition for resources critical in mate choice. Such effects could be common, considering the prevalence across organisms of male resource defence. Thus, more attention should be directed to the effects of environmental disturbances on resource competition, as well as to the consequences that these effects may have for the evolutionary trajectory and viability of populations.

\section{References}

Andersen, J. H., Carstensen, J., Conley, D. J., Dromph, K., Fleming-Lehtinen, V., Gustafsson, B. G., Josefson, A. B., Norkko, A., Villnäs, A. and Murray, C. 2017. Long-term temporal and spatial trends in eutrophication status of the Baltic Sea. - Biol. Rev. 92: 135-149. 
Andersson, M. 1994. Sexual selection. - Princeton University Press.

Cally, J. G., Stuart-Fox, D. and Holman, L. 2019. Meta-analytic evidence that sexual selection improves population fitness. - Nat. Commun. 10: 10.

Candolin, U. 1997. Predation risk affects courtship and attractiveness of competing threespine stickleback males. - Behav. Ecol. Sociobiol. 41: 81-87.

Candolin, U. 1999. Male-male competition facilitates female choice in sticklebacks. - Proc. R. Soc. Lond. B 266: 785-789.

Candolin, U. 2000. Male-male competition ensures honest signaling of male parental ability in the threespined stickleback. - Behav. Ecol. Sociobiol. 49: 57-61.

Candolin, U. 2004. Effects of algae cover on egg acquisition in male three-spined stickleback. - Behaviour 141: 1389-1399.

Candolin, U. 2009. Population responses to anthropogenic disturbance: lessons from three-spined sticklebacks Gasterosteus aculeatus in eutrophic habitats. - J. Fish Biol. 75: 2108-2121.

Candolin, U. 2019. Mate choice in a changing world. - Biol. Rev. 94: 1246-1260.

Candolin, U. and Heuschele, J. 2008. Is sexual selection beneficial during adaptation to environmental change? - Trends Ecol. Evol. 23: 446-452.

Candolin, U., Nieminen, A. and Nyman, J. 2014. Indirect effects of human-induced environmental change on offspring production mediated by behavioural responses. - Oecologia 174: 87-97.

Candolin, U., Salesto, T. and Evers, M. 2007. Changed environmental conditions weaken sexual selection in sticklebacks. - J. Evol. Biol. 20: 233-239.

Candolin, U., Tukiainen, I. and Bertell, E. 2016. Environmental change disrupts communication and sexual selection in a stickleback population. - Ecology 97: 969-979.

Candolin, U. and Vlieger, L. 2013. Estimating the dynamics of sexual selection in changing environments. Evol. Biol. 40: 589-600.

Candolin, U. and Voigt, H. R. 2001. No effect of a parasite on reproduction in stickleback males: a laboratory artefact? - Parasitology 122: 457-464.

Candolin, U. and Wong, B. B. M. 2019. Mate choice in a polluted world: consequences for individuals, populations and communities. - Phil. Trans. R. Soc. B. 374: 20180055.

Carstensen, J., Klais, R. and Cloern, J. E. 2015. Phytoplankton blooms in estuarine and coastal waters: Seasonal patterns and key species. - Estuar. Coast. Shelf Sci. 162: 98-109.

Coomes, C. M., Danner, R. M. and Derryberry, E. P. 2019. Elevated temperatures reduce discrimination between conspecific and heterospecific sexual signals. - Anim. Behav. 147: 9-15.

des Aunay, G. H., Slabbekoorn, H., Nagle, L., Passas, F., Nicolas, P. and Draganoiu, T. I. 2014. Urban noise undermines female sexual preferences for low-frequency songs in domestic canaries. - Anim. Behav. 87: 67-75.

Engström-Öst, J. and Candolin, U. 2007. Human-induced water turbidity alters selection on sexual displays in sticklebacks. - Behav. Ecol. 18: 393-398.

Finni, T., Kononen, K., Olsonen, R. and Wallstrom, K. 2001. The history of cyanobacterial blooms in the Baltic Sea. - Ambio 30: 172-178.

Fleming-Lehtinen, V. and Laamanen, M. 2012. Long-term changes in Secchi depth and the role of phytoplankton in explaining light attenuation in the Baltic Sea. - Estuar. Coast. Shelf Sci. 102: 1-10.

Gobler, C. J., Doherty, O. M., Hattenrath-Lehmann, T. K., Griffith, A. W., Kang, Y. and Litaker, R. W. 2017. Ocean warming since 1982 has expanded the niche of toxic algal blooms in the North Atlantic and North Pacific oceans. - Proc. Natl. Acad. Sci. USA 114: 4975-4980.

Granqvist, M. and Mattila, J. 2004. The effects of turbidity and light intensity on the consumption of mysids by juvenile perch (Perca fluviatilis L.). - Hydrobiologia 514: 93-101.

Gurule-Small, G. A. and Tinghitella, R. M. 2018. Developmental experience with anthropogenic noise hinders adult mate location in an acoustically signalling invertebrate. - Biol. Lett. 14: 4.

Heuschele, J., Mannerla, M., Gienapp, P. and Candolin, U. 2009. Environment-dependent use of mate choice cues in sticklebacks. - Behav. Ecol. 20: 1223-1227.

Heuschele, J., Salminen, T. and Candolin, U. 2012. Habitat change influences mate search behaviour in three-spined sticklebacks. - Anim. Behav. 83: 1505-1510. 
Holman, L. and Kokko, H. 2013. The consequences of polyandry for population viability, extinction risk and conservation. - Phil. Trans. R. Soc. B. 368.

Iglesias-Carrasco, M., Head, M. L., Jennions, M. D. and Cabido, C. 2017. Secondary compounds from exotic tree plantations change female mating preferences in the palmate newt (Lissotriton helveticus). - J. Evol. Biol. 30: 1788-1795.

Järvenpää, M. and Lindström, K. 2004. Water turbidity by algal blooms causes mating system breakdown in a shallow-water fish, the sand goby Pomatoschistus minutus. - Proc. R. Soc. Lond. B. 271: 2361-2365.

Kingsolver, J. G., Hoekstra, H. E., Hoekstra, J. M., Berrigan, D., Vignieri, S. N., Hill, C. E., Hoang, A., Gibert, P. and Beerli, P. 2001. The strength of phenotypic selection in natural populations. - Am. Nat. 157: 245261.

Korpinen, S., Meski, L., Andersen, J. H. and Laamanen, M. 2012. Human pressures and their potential impact on the Baltic Sea ecosystem. - Ecol. Indic. 15: 105-114.

Lane, S. M. and Briffa, M. 2018. How does the environment affect fighting? The interaction between extrinsic fighting ability and resource value during contests. - J. Exp. Biol. 221: 8 .

Le Cren, E. D. 1951. The length-weight relationship and seasonal cycle in gonad weight and condition in the perch (Perca fluviatilis). - J. Anim. Ecol. 20: 201-219.

Martinez-Ruiz, C. and Knell, R. J. 2017. Sexual selection can both increase and decrease extinction probability: reconciling demographic and evolutionary factors. - J. Anim. Ecol. 86: 117-127.

Martinossi-Allibert, I., Rueffler, C., Arnqvist, G. and Berger, D. 2019. The efficacy of good genes sexual selection under environmental change. - Proc. R. Soc. Lond. B 286: 9.

Myhre, L. C., Forsgren, E. and Amundsen, T. 2013. Effects of habitat complexity on mating behavior and mating success in a marine fish. - Behav. Ecol. 24: 553-563.

O'Neil, J. M., Davis, T. W., Burford, M. A. and Gobler, C. J. 2012. The rise of harmful cyanobacteria blooms: The potential roles of eutrophication and climate change. - Harmful Algae 14: 313-334.

Parrett, J. M., Mann, D. J., Chung, A. Y. C., Slade, E. M. and Knell, R. J. 2019. Sexual selection predicts the persistence of populations within altered environments. - Ecol. Lett. 22: 1629-1637.

Rosenthal, G. G. and Stuart-Fox, D. 2012. Environmental disturbance and animal communication. - In: Candolin, U. and Wong, B. B. M. (eds.), Behavioural responses to a changing world: mechanisms and consequences. Oxford Unviersity Press, pp. 16-31.

Ryder, T. B. and Sillett, T. S. 2016. Climate, demography and lek stability in an Amazonian bird. - Proc. R. Soc. Lond. B 283: 9.

Schmidt, R., Morrison, A. and Kunc, H. P. 2014. Sexy voices - no choices: male song in noise fails to attract females. - Anim. Behav. 94: 55-59.

Seehausen, O., Alphen, J. J. M. and Witte, F. 1997. Cichlid fish diversity threatened by eutrophication that curbs sexual selection. - Science 277: 1808-1811.

Sliwinska-Wilczewska, S., Cieszynska, A., Konik, M., Maculewicz, J. and Latala, A. 2019. Environmental drivers of bloom-forming cyanobacteria in the Baltic Sea: Effects of salinity, temperature, and irradiance. - Estuar. Coast. Shelf Sci. 219: 139-150.

Sundin, J., Aronsen, T., Rosenqvist, G. and Berglund, A. 2017. Sex in murky waters: algal-induced turbidity increases sexual selection in pipefish. - Behav. Ecol. Sociobiol. 71: 8.

Swaddle, J. P., Francis, C. D., Barber, J. R., Cooper, C. B., Kyba, C. C. M., Dominoni, D. M., Shannon, G., Aschehoug, E., Goodwin, S. E., Kawahara, A. Y., Luther, D., Spoelstra, K., Voss, M. and Longcore, T. 2015. A framework to assess evolutionary responses to anthropogenic light and sound. - Trends Ecol. Evol. 30: 550-560.

Thomas, M. K., Kremer, C. T., Klausmeier, C. A. and Litchman, E. 2012. A Global Pattern of Thermal Adaptation in Marine Phytoplankton. - Science 338: 1085-1088.

Tinbergen, N. 1951. The Study of Instinct. - Clarendon Press.

van der Sluijs, I., Gray, S. M., Amorim, M. C. P., Barber, I., Candolin, U., Hendry, A. P., Krahe, R., Maan, M. E., Utne-Palm, A. C., Wagner, H. J. and Wong, B. B. M. 2011. Communication in troubled waters: responses of fish communication systems to changing environments. - Evol. Ecol. 25: 623-640.

Vlieger, L. and Candolin, U. 2009. How not to be seen: does eutrophication influence stickleback sneaking behaviour? - J. Fish Biol. 75: 2163-2174. 
449 Wong, B. B. M., Candolin, U. and Lindström, K. 2007. Environmental deterioration compromises socially450 enforced signals of male quality in three-spined sticklebacks -Am. Nat. 170: 184-189.

451 Wootton, R. J. 1984. The functional biology of sticklebacks. - Croom Helm.

452 